\title{
Exploring occupational therapy students' perceptions of spirituality in occupational therapy groups: a qualitative study
}

Thuli G. Mthembu, Lisa Wegner, and Nicolette V. Roman

\begin{abstract}
An exploratory-descriptive qualitative research approach explored occupational therapy students' perceptions of spirituality in occupational therapy groups during the group fieldwork process. Four focus group discussions were conducted and thematically analyzed. Four themes related to the metaphoric expressions of spirituality emerged: (1) occupational group therapy is a vehicle for spirituality; (2) spiritual journey in occupational therapy groups; (3) engaging in occupations facilitates spirituality; and (4) make use of the resources to service the driver and vehicle. Occupational therapy groups appeared to be the facilitators of spirituality through engagement in occupations, which enhanced quality of life, health, and well-being of group members.
\end{abstract}

\section{Introduction}

Occupational therapy groups have been used to enhance group members' insight into their individual problems so they may be assisted in discovering themselves through expression of their feelings (FinLay, 1993; Joyce \& Warren, 2016). Occupational therapy groups provide group members with opportunities for connectedness, socialization, and learning by observing other group members (FinLay, 1993; Kang, 2003). Therefore, Schneider Corey, Corey, and Corey (2013) and FinLay (1993) emphasized that group members gain knowledge about themselves and their personal identity through interactions with other members. Previous studies have indicated that occupational therapy groups seem to be used more in mental health facilities and rehabilitation centers for youth at-risk of substance abuse (Bell et al., 2015; Carroll, 2015).

The facilitators of occupational therapy groups should ethically respect and acknowledge the differences among group members based on the members' religion, spirituality, and morals (Corey, Schneider Corey, Corey, \& Callanan, 2015; Schneider Corey et al., 2013; Thompson \& MacNeil, 2006; Udell \& Chandler, 2000). Occupational therapy groups are regarded as a supportive environment that seem to allow, both individually and collectively, enhancement of psychological and spiritual well-being of group members (Kang, 2003). 
Table 1. Themes with metaphors, categorles, and subcategorles.

\begin{tabular}{|c|c|c|}
\hline Themes & Categorles & Subcategorles \\
\hline $\begin{array}{l}\text { Occupational therapy groups are a } \\
\text { vehicle for spirituality } ¥ \text { (The } \\
\text { vehicle) }\end{array}$ & $\begin{array}{l}\text { Self-awareness } \\
\text { Meaning and purpose } \\
\text { Connectedness within group } \\
\text { "Psychosoclal Interactive } \\
\text { approach" (The engine) } \\
\text { "Stages of group development" } \\
\text { (The wheels) }\end{array}$ & $\begin{array}{l}\text { Elements of spirituality } \\
\text { "Know themselves" } \\
\text { "Sense of purpose" } \\
\text { "Spirituality essence" } \\
\text { Holistic } \\
\text { Others } \\
\text { Community } \\
\text { Evocattive therapy } \\
\text { Creativity } \\
\text { Spontanelty } \\
\text { Forming stage } \\
\text { Storming stage } \\
\text { Norming stage } \\
\text { Performing stage }\end{array}$ \\
\hline $\begin{array}{l}\text { Spiritual journey in occupational } \\
\text { therapy groups (The route with } \\
\text { a map, rules, and driving } \\
\text { forces for the same } \\
\text { direction) }\end{array}$ & $\begin{array}{l}\text { "Therapeutic use of self as part } \\
\text { of leadership style' (The } \\
\text { driver/faciltotor) } \\
\text { "Spirituality is a foundation of } \\
\text { Yalom's curative factors" (The } \\
\text { driving forces with ripple effect) }\end{array}$ & $\begin{array}{l}\text { "Democratic leadership" } \\
\text { Leadership functions } \\
\text { Universality } \\
\text { Group cohesion } \\
\text { Altrulsm } \\
\text { Imparting information } \\
\text { Reflective appreclation } \\
\text { Interpersonal learning } \\
\text { Catharsis }\end{array}$ \\
\hline $\begin{array}{l}\text { Engagement in occupations } \\
\text { facilitates spirituality (The } \\
\text { travelers' fuel and energy for } \\
\text { reaching the destination) }\end{array}$ & $\begin{array}{l}\text { Person-centered and humanistic } \\
\text { approaches (The travelers) } \\
\text { Meaning and purpose of } \\
\text { occupations }\end{array}$ & $\begin{array}{l}\text { Group members' autonomy } \\
\text { Being human } \\
\text { Doing occupation } \\
\text { Belonging to the group } \\
\text { Becoming } \\
\text { Bellefs } \\
\text { Values } \\
\text { Spintual } \\
\text { Mental health settings } \\
\text { Environment }\end{array}$ \\
\hline $\begin{array}{l}\text { Make use of the resources to service } \\
\text { the driver and vehide (The } \\
\text { motor mechanic services to } \\
\text { nurture and care) }\end{array}$ & $\begin{array}{l}\text { "Need to get a spiritual leader } \\
\text { Involved" } \\
\text { Resources in the settings } \\
\text { Familles of group members }\end{array}$ & $\begin{array}{l}\text { Referral system } \\
\text { Humans } \\
\text { Burnout } \\
\text { Affectlve } \\
\text { Stress } \\
\text { Support services for students } \\
\quad \text { and therapist }\end{array}$ \\
\hline
\end{tabular}

Note. Quotation marks Indicate participants' verbatim quotes. Italics explain the metaphors.

This supports Kang's (2003) view of occupational abundance, which refers to the rich availability of opportunities to participate in occupations of choice and a spiritually-oriented approach to life. Spirituality is defined by Janse van Rensburg, Poggenpoel, Myburgh, and Szabo (2014) as:

Progressive individual or collective inner capacity, consciousness or awareness of transcendence. It also consists of relational aspects or connectedness and essentially exists as a process, representing growth, or a journey. This capacity, consciousness and connectedness provide the motivating drive for living and constitute the source from which meaning and purpose is derived. (p. 1849)

There are seven dimensions of spirituality in occupational therapy, which include suffering, becoming, meaning, being, centeredness, connectedness, and transcendence (Jones, 2016; Kang, 2003). The phenomenon of spirituality in occupational therapy, however, has previously been explored from the perspectives of clients and occupational therapists (Hess 
\& Ramugondo, 2014; Jones, 2016; Smith \& Suto, 2014; Soomar, 2015; Suto \& Smith, 2014; Wilding, 2007). Likewise, there is limited research on occupational therapy students' perspectives concerning spirituality in occupational therapy groups during fieldwork where they use group process. Soomar's (2015) study indicated there is little previous research in the area of spirituality in occupational therapy groups and educational programs in a South African context. This might be a challenge for occupational therapy students to address spiritual issues competently and wisely in occupational therapy groups. Therefore, in this study, the following question is addressed: What are occupational therapy students' perceptions of spirituality in occupational therapy groups? These perceptions can provide occupational therapy educators with additional resources and strategies that can be integrated by an occupational therapy education program, and thus lead to improved competence of future occupational therapists.

Spirituality is regarded as a form of being that provides the meaning that underpins doing and engagement in purposeful occupation (Donica, 2008; McColl, 2011; Polatajko, Townsend, \& Craik, 2007; Wilding, 2007). Therefore, social participation is one of the meaningful occupations that facilitates spirituality through the connectedness between occupational therapists, group members, and their families (Cole \& Donohue, 2011; Smith \& Suto, 2014; Wilding, 2007). Similarly, occupational therapy groups are grounded within the psychosocial interactive approach, which promotes social interactions, relationships, communication, connectedness, and the occupational performance among human beings (Carroll, 2015; Dawson, 1993; Duncombe \& Howe, 1985; Stein \& Tallant, 2013). Most previous studies on occupational therapy groups focused on the psychosocial interactive approach and life skills such as social skills (Cole \& Donohue, 2011), stress management, self-knowledge, self-image, assertiveness, communication, day planning, conflict management, and boundaries (Carroll, 2015). Although the psychosocial interactive approach has been widely used in occupational therapy groups, there is a rarity in empirical research with regards to spirituality within these groups. Therefore, this study sought to gain insight into the perceptions of occupational therapy students to obtain comprehensive descriptions of their perceptions about spirituality in occupational therapy groups using a psychosocial interactive approach.

The psychosocial interactive approach seems to be congruent with Yalom's curative factors in groups (Stein \& Tallant, 1988; Yalom \& Leszcz, 2005). The psychosocial interactive approach emphasizes that human beings can only reach a good quality of life through meaningful relationships with others through curative factors. The curative factors include group cohesion, universality, installation of hope, corrective recapitulation of the family, development of social techniques, imitative behavior, interpersonal learning, catharsis, imparting information, altruism, and existential factors and changes, as well as new insights that are achieved in an occupational therapy group (O'Donnell, 2008; Stein \& Tallant, 1988; Yalom \& Leszcz, 2005; Zinnbauer \& Camerota, 2004). Previous studies on group process reported that these curative factors seem to assist group members in occupational therapy groups to progress through the four stages of group development such as forming, storming, norming, and performing (Marmarosh, Holtz, \& Schottenbauer, 2005; Yalom \& Leszcz, 
2005). A number of studies, however, show there are associations between curative factors and spirituality in occupational therapy groups, which perhaps only apply to clients and therapists (O'Brien, 2013; O'Donnell, 2008; Smith \& Suto, 2014; Soomar, 2015; Suto \& Smith, 2014). Although these studies reported many interesting results, few publications have explored how occupational therapy students perceive spirituality in occupational therapy groups. Therefore, this study aimed to explore occupational therapy students' perceptions of spirituality in occupational therapy groups during fieldwork.

\section{Methodology}

\section{Research setting}

This study was conducted in an Occupational Therapy Department at a university in the Western Cape Province, South Africa. Occupational therapy students use group process to apply their knowledge and skills learned in the classroom to fieldwork practice during a series of 6- to 8-week fieldwork placements. They take into account the clients' context and needs (De Jongh, 2009). This is referred to as the group fieldwork process.

\section{Ethics statement}

Ethical approval for this study was obtained from the University of the Western Cape Research Ethics Committee (Protocol REC14/4/18). Participants were informed that their participation was voluntary and that they were free to withdraw at any time without repercussions. Informed consent was obtained from all participants prior to the focus group discussions (FGDs). Anonymity was used to protect participants' confidentiality and privacy through the use of identification numbers with the excerpts. The data were stored in the computers of all three authors protected with a password to prevent any identification of the participants.

\section{Research design}

This study used an exploratory-descriptive qualitative research approach to explore students' perceptions of spirituality in occupational therapy groups during the group fieldwork process (Grove, Burns, \& Gray, 2013). Additionally, an interpretive worldview was used in order to acquire a deeper understanding of, and insight into, the phenomenon of spirituality in occupational therapy groups (Terre Blanche, Kelly, \& Durrheim, 2006).

\section{Participants}

Purposive sampling was used to recruit participants $(n=39)$ for the study. The inclusion criteria: full-time registered undergraduate third-year and fourth-year occupational therapy students between 2014 and 2016. Furthermore, a group of 10 participants out of the 39 participants who were then in their fourth-year were selected after 9 months for a follow-up FGD. This group of 10 participants were selected because they had an opportunity to lead occupational therapy groups in mental health facilities. 


\section{Data collection}

Four FGDs were used to gather the occupational therapy students' views about spirituality in their group fieldwork process, and these discussions lasted between 50 to 80 minutes. Group one included 11 third-year students; group two consisted of seven third-year students; and group three consisted of 11 fourth-year students. From the analysis of these three groups, there were metaphorical expressions that emerged from the previous FGDs stating that occupational therapy groups are a "vehicle" for spirituality, and are a "spiritual journey in groups." Subsequently, the following year, a follow-up FGD with some of the same participants $(\mathrm{n}=10)$, who were then in fourth year, was conducted to obtain a deeper understanding of their views regarding the metaphoric expressions of spirituality in groups. This group lasted approximately 80 minutes. All the FGDs were recorded and transcribed verbatim.

\section{Data analysis and trustworthiness}

All transcripts were imported into, and managed in, Atlas.ti 7 software (Scientific software, 2016; http://www.atlas.com/index.html) in preparation for the data analysis. Six phases of thematic analysis were used to analyze the data in an iterative manner (Braun \& Clarke, 2006) in conjunction with metaphoric expressions to obtain an in-depth understanding of, and insight into, the construct phenomenon of spirituality (Pishghadam \& Pourali, 2011). In the first phase, the first author (TGM) started by reading through the transcripts and listening to the recorded tapes to become familiar with the data in order to uncover and analyze the hidden meanings and views. Additionally, there were metaphorical expressions that were noticed in the segments of the qualitative text from the participants. These metaphors included statements such as "occupational therapy groups are a 'vehicle' for spirituality"; "group process as both 'spiritual journey in groups' and 'ongoing development"; "connections as a 'driving force"; "group growing in the same way as a "direction." This led the first author (TGM) to the second phase in order to generate initial codes aligned with the metaphoric expressions generated by the participants. Consequently, the codes were grouped based on the metaphoric phrases, similarities, and relationships among them to form categories (known as families in Atlas.ti 7). Subsequently, in the third phase, searching of themes was based on the metaphoric phrases in order to ensure all the themes were related to each other. Thereafter, in the fourth phase, reviewing of themes was conducted in consultation with the participants as part of enhancing credibility through member checking. This assisted in validating the accuracy of the findings as a true reflection of the participants' words. Similarly, the use of peer debriefing and multiple researcher perspectives allowed us to review and verify the themes to enhance dependability through an audit trail of the process followed in analyzing the data. Moreover, confirmability was ensured through discussions with the three researchers in order to reach and confirm consensus about the findings of the study by peer debriefing. Then, in the fifth phase, themes were defined and named through the use of participants' responses known as in-vivo quotes. Eventually, a report was written in a narrative using a metaphorical approach to organize the themes and their relationships-supported by excerpts as evidence of the data. 


\section{Description of the participants' metaphors}

The metaphors brought an understanding of the tacit knowledge of the students' perceptions of spirituality in occupational therapy groups (Ellis, 2008; Pishghadam \& Pourali, 2011; Saban, 2004). The participants used the vehicle as a symbol of occupational therapy groups; they indicated that (the vehicle) seemed to assist group members to experience their spirituality. This metaphor of a vehicle emerged from the participants when they were responding to a question (How you think spirituality comes out in occupational therapy groups?).

In the participants' discourse, they highlighted the view that the engine symbolized the psychosocial interactive approach and the wheels of the vehicle represented the stages of group development in occupational therapy groups. The route with map, rules, and driving in the same direction denoted the spiritual journey in occupational therapy groups. The driver/facilitator of the vehicle signified the therapeutic use of self as part of leadership style. Additionally, they pointed out that the driving forces appeared as enablers for group members and the leader with ripple effect symbolized Yalom's curative factors. The travelers' fuel and energy for reaching the destination were participants' perceptions that represented engagement in occupations facilitating spirituality during occupational therapy groups. The travelers emerged as a symbol that represented the person and humanistic approaches in groups. Finally, the participants' discourse indicated that the motor mechanic serves to nurture and care, and symbolized the use of resources to service the driver (facilitators and the vehicle [the groups]).

\section{Findings}

Four themes related to the metaphoric expressions of spirituality emerged from the data analysis: (1) occupational therapy groups are a vehicle for spirituality; (2) spiritual journeys occur in occupational therapy groups; (3) engaging in occupations facilitates spirituality; and (4) make use of the resources to service the driver and vehicle. Therefore, the research findings are presented in a form of metaphors that were used by participants to illustrate their perceptions of spirituality in occupational therapy groups, as presented in Table 1.

\section{Occupational therapy groups are a vehicle for spirituality}

The first theme highlights the participants' perceptions: In this case, the vehicle symbolizes that occupational therapy groups are a vehicle for spirituality. Occupational therapy groups were perceived as enablers of spirituality, as they assisted group members to find meaning and purpose in life. Similarly, the participants believed that spirituality seemed to facilitate a sense of connectedness and a sense of belonging for group members when they were part of an occupational therapy group. As a result, the participants believed that spirituality was a significant asset because it led group members to interact with each other during occupational therapy groups.

We use it [spirituality] as a vehicle in therapy to get them there where they need to be. Spirituality plays a big part within the groups as an entity because they [group members] can relate to one another. (Fourth-year student 10, personal communication, 2015) 
The participants perceived the occupational therapy group as a facilitator of self-awareness that enhances group members' sense of self and coping skills. Additionally, the participants believed the occupational therapy groups seemed to assist group members in finding meaning and purpose through their participation.

They [group members] are able to cope with life if they experience the sense of self, and that is spirituality as a sense of purpose and self. If we start learning about ourselves and our self-esteem and those things, spirituality is involved with that. (It) equips them [group members] to know about themselves and that increases their spirituality. (Fourth-year student 8, personal communication, 2016)

He likes to take a walk and just listens to himself while experiencing the sense of realization through that he is tapping in his spirituality as part of sense of self [sic]. (Fourth-year student 1, personal communication, 2016)

You need to be able to find meaning together as a group then you go forward in the next stage of the group when you develop together as a group. (Fourth-year student 10, personal communication, 2016)

Participants highlighted the view that being part of the vehicle contributed significantly to the group members' connectedness because the driving forces facilitated the relationships in the groups.

The essence of spirituality brings the connections and binds people together. (Fourth-year student 4, personal communication, 2016)

Likewise, another participant provided a rationale about why occupational therapy groups are considered a vehicle for spirituality. The participant explained that group members from diverse backgrounds share their lives with each other, which creates connections among them.

Groups are a vehicle for our spirituality, it's that thing of bringing different forces that are in everybody and transferring those forces amongst each other. (Fourth year student 1, personal communication, 2016)

It was evident that the meaningful and purposeful connections were the driving forces that pulled the group members together when they participated in the occupational therapy groups and then enabled them to embark on a spiritual journey.

In the participants' discourse, it was noted that the engine symbolized the psychosocial interactive approach. This metaphor was used to express participants' perception of the importance of the psychosocial interactive approach in an occupational therapy group, and it was shared by one participant who has used the psychosocial interactive model in practice. This participant believed the psychosocial interactive model supports spirituality in occupational therapy groups. The engine as a metaphor denoted a psychosocial interactive approach and assisted in facilitating group members' self-reflection and self-discovery.

The psychosocial interactive model promotes group members to explore their own emotions that they often hideaway and locked it for a long time. The model assists group members to experience their emotions, by doing that, I can see that is a drive for spirituality. (Fourth-year student 8, personal communication, 2016) 
The wheels of the vehicle metaphor symbolize the stages of group development in occupational therapy groups. Some participants employ the wheels metaphor to describe their perception of group development stages, which include forming, storming, norming, and performing. The participants believed these stages of group development appeared as enablers for group members to achieve their goals of a better quality of life, health, and wellbeing.

The group development is an ongoing process that assists group members to become spiritual at the same time. The group comes together because there are common goals include to get better, to get out of the hospital, as well as to be healed. Therefore, they [group members] become one so that they work towards to reach their goals. (Fourth-year student 6, personal communication, 2016)

The wheels metaphor was used by the participants to express their perceptions of how their spirituality developed during the stages of group development. Two participants explained sharing their views based on their fieldwork experiences of running occupational therapy groups in mental health facilities.

Spirituality is something that can be shown throughout all the stages of group development. In the forming stage, group members get an opportunity to know each other and they can realize that they are spiritual beings through the feedback they receive from other group members during their discussion in a group.

The performing stage, the whole group has understanding of their spirituality.

The group members seem to know whether they are spiritual or not. It helps the group to perform because they are at stage where they understand themselves, as they have connected with each other, and they aware of basic norms of how to deal with the situations.

Storming stage, this occurs when the group members start to have some conflicts and then they are experiencing issues as individuals, they understand their spirituality... deal with the situations if someone speaks about something that is provoking. (Fourth-year student 5, personal communication, 2016)

Another participant shared the view that the norming stage assists group members to reach consensus about certain issues within the group. The participant felt that this was the stage in which group members tend to experience a sense of belonging as part of the occupational therapy group. Additionally, the participant provided her insightful explanations to demonstrate a thorough knowledge of social, cultural, and spiritual issues relating to the occupational therapy group. It was evident that the norming stage of group development appeared as a facilitator of attributes such as sensitivity, tolerance, and acceptance.

The norming stage is where the Bennett's model (Bennett, 1993) of cultural sensitivity comes in. This is where spiritual sensitivity occurs, you are accepting that the person's spirituality is different from mine but is fine, as we all human beings. We can link the culture, to spirituality, to religion to all other stuff such as doing, becoming, being and belonging. (Fourth-year student 3, personal communication, 2016)

\section{Spiritual journey in occupational therapy groups}

The second theme identified was a metaphor of the route to be traveled with a map, rules, and driving events in the same direction and denoting the spiritual journey in occupational therapy groups. This spiritual journey metaphor indicates that the participants viewed occupational therapy groups as an enabler for a purpose, guidance, and spiritual care. The participants used the metaphor to emphasize the importance of group process whereby the 
group members are given opportunities to work together as a team. The participants indicated the group process promotes meaningful and purposeful relationships for mutual understanding and communication. The theme comprises therapeutic use of self as part of leadership style and Yalom's curative factors.

Group process is used to guide the spiritual journey in groups and the group members work together like us sitting in a group today we are talking about spirituality together that forms part of the group's spirituality. (Third-year student 8, personal communication, 2015)

The driver/facilitator of the vehicle metaphor signified the therapeutic use of self as part of a good leadership style in occupational therapy groups. The participants viewed their relationships with their group members as an integral part of the spiritual journey in groups. As a result, these participants felt that their roles as drivers were centered on how they use themselves to drive the group in a meaningful and purposeful direction to reach their destination. According to the participants' discourse, it has been noted that the occupational therapists should understand their stance regarding spirituality in order to facilitate the journey. This indicates that it would be helpful for occupational therapists to spend some time in seeking to understand who they are as part of their personal and professional identities.

The type of leadership style has something to do with spirituality because you need to understand the group members so that you may be able to choose an appropriate leadership style. (Fourth-year student 10, personal communication, 2016)

For occupational therapists to facilitate spirituality in groups, you have to understand your own spirituality. If you don't have spiritual beliefs but you have to understand you are not a spiritual being but a mindful one. (Fourth-year student 5, personal communication, 2016)

Additionally, the participants emphasized the importance of being mindful of the variety of responsibilities and expectations that occupational therapists need to lead and guide the groups. This supports the driver/facilitator metaphor as participants expressed a perception of themselves as effective change agents within occupational therapy groups. It was clear that the participants valued autonomy and empathy to ensure group members were provided with opportunities to participate in a journey of discovery.

As a therapist your job is to take the group through the journey of discovery and allow them [group members] to go through the stages of group development so that they are able to experience being part of the group. (Fourth-year student 6, personal communication, 2016)

Participants used the driving forces to symbolize their perception of spirituality as a foundation of Yalom's curative factors. Additionally, the participants accentuated a number of Yalom's curative factors (Yalom \& Leszcz, 2005; Zinnbauer \& Camerota, 2004) that contributed significantly to the spiritual journey in occupational therapy groups and facilitated group development. The curative factors that the participants perceived as being grounded within spirituality included universality, altruism, group cohesion, installation of hope, interpersonal learning, imparting information, catharsis, and reflective appreciation. 
Spirituality is a foundation of those Yalom's curative factors, and spirituality is the foundation of meaning in a group. (Fourth-year student 9, personal communication, 2016)

Therapeutic [curative] factors are part of the group development and they are the driving force of group development. (Fourth-year student 6, personal communication, 2016)

Spirituality was consistently associated with universality, altruism, and group cohesion. The participants' discourse illustrated that belonging to occupational therapy groups enables group members to share similar experiences about life; as a result, they find meaning and purpose in the relationship. Another participant also provided a rationale for the importance of sharing in a group as it strengthens group cohesion and the sense of belonging.

When the group is building the cohesive unit they all share same stories in the same way and they also internalize feelings together and then together the group reaches a certain level of spirituality is like a ripple effect. (Fourth-year student 8, personal communication, 2016)

When people start sharing about their spirituality the cohesion happens and you realize I am actually doing this too to improve my spirituality and to better my mindfulness (Fourth-year student 3, personal communication, 2016)

Participants reported that installation of hope enabled group members to connect with each other. This indicates the group members seemed to have faith that they bring into the occupational therapy group to assist them to solve their problems.

Realization that somebody else is experiencing something similar and then they are able to instil [sic] that hope and that is spiritual connection as it is more like a beacon of hope. (Fourth-year student 4, personal communication, 2016)

This seems to support the metaphor in which participants perceived the occupational therapy group as a vehicle for spirituality that enhances group members' well-being and satisfaction. The participants pointed out the importance of spirituality in group therapy as they noticed that often group members share something common about their condition, which is related to universality. Consequently, this could mean that group members were able to understand each other as they share similar problems and challenges.

The group is growing as a whole and is not about the individual member but the group ... not driving in a different direction and growing in a different way but the group is growing in the same way finding meaning in the group, and their existence in a group rely on each other for advice. They rely on each other and they become a driving force. (Fourth-year student 8, personal communication, 2016)

The participants further indicated that the group's diversity did not influence members' participation in the spiritual journey in occupational therapy groups; instead, it strengthened the sense of belonging. This meant that the group members had an opportunity to experience a sense of acceptance and group solidarity to support and encourage each other.

Within the groups that I was running, I think spirituality played an important role as the group members were able to identify with one another along the lines that they were all there for the same reason. Although they came from different backgrounds and different situations at home, but they all had common struggles related to their diagnosis of depression and the feelings of not wanting to do anything anymore. 
Therefore, I think that relationship allows them to share with one another. (Fourth-year student 11, personal communication, 2016)

\section{Engagement in occupations facilitates spirituality}

The third theme highlights the participants' perceptions about how engagement in occupations facilitates spirituality; this is symbolized by the travelers' fuel and energy for reaching the travel destination. The participants expressed their views and reasons by using metaphors to explain why occupational therapy groups are regarded as facilitators of spirituality. Therefore, the participants used the travelers' metaphor to express their perception of how both holistic and person-centered approaches were considered as part of the groups. The meaningful and purposeful occupations that occupational therapists used in groups to facilitate spirituality also supposed this.

The participants responded to the question: What is it about occupational therapy groups that facilitate spirituality? The participants' responses used the travelers' metaphor to emphasize the role of occupational therapy groups as facilitators of spirituality. The participants indicated that as occupational therapy students, they believed human beings need to be regarded as role players of their own lives. This is further explained by the participants' responses when they reflect on the importance of autonomy in allowing group members to express their needs, which also includes spirituality. As a result, the participants reported that the group members found meaning and sense of belonging if they recognized that their needs are considered as important in occupational therapy groups.

We [occupational therapists] use holistic and person-centered approaches for me that is spiritual because we allow group members to be who they are and work from who they are. We also work on what they want for themselves to find meaning and belonging. (Fourth-year student 8, personal communication, 2015)

Viewing human beings as occupational beings is a core of the occupational therapy profession. Our main goal in occupational therapy is to assist our clients to find meaning on what they are doing but not telling them what to do by allowing them to identify their own purpose. (Fourth-year student 6, personal communication, 2016).

Some participants explained that both occupations and spirituality are integral components of the occupational therapy profession because they provide the group members with time and space to engage in meaningful social participation activities.

Both occupations and spirituality link with how somebody can cope with the kind of trauma, then bring back meaning. (Fourth-year student 2, personal communication, 2016)

In occupational therapy, we look at the occupations that group members engaged in, for instance, we bring the occupation of social participation as we know we are social and spiritual beings, we're learning from each other, we're constantly forming the norm, and finding the society norms around us. Hence, we use psychosocial interactive in occupational therapy group model because it is basically emphasises on facilitating interaction, and discussion, and is not about me directing questions. I always encourage group members to share their stories with each other. I think the model is great for spirituality that you want to get out of it. (Fourth-year student 8, personal communication, 2016) 
The participants valued the use of occupations during occupational therapy groups to facilitate spirituality. This meant that there was meaningful and purposeful engagement and participation to enhance group members' health, quality of life, and well-being. According to the participants' discourse, occupations such as painting and drawing enabled group members to reflect about their experiences in occupational therapy. This is consistent with evocative therapy used in occupational therapy groups through the psychosocial interactive approach to facilitate spirituality.

Drawing [using] the Kawa river model with various components like rocks as obstacles in life. So I think that kind of an activity will bring self-reflection is there to facilitate spirituality. By engaging in painting and drawing activity, group members draw the sun as their dreams they need to achieve, so through that activity or story actually you're reflecting and spirituality comes out. (Fourth-year student 9, personal communication, 2016)

Evocative therapy involves doing an activity in a session like that you doing evocative without you thinking you doing it. (Fourth-year student 3, personal communication, 2016)

One participant, however, cautioned that students need to be taught carefully about how to use evocative therapy during occupational therapy groups in order to prevent harming group members.

To finish off with evocative therapy, as a student therapist you need to be informed how to deal with that in theory, and guidelines need to be provided because going there winging it is going to be a problem. (Fourthyear student 9, personal communication, 2016)

Participants' discourse pointed out that there is a relationship between occupational therapy groups, evocative therapy, the psychosocial approach, and occupations, which contributed significantly to the facilitation of spirituality. This relationship appeared to enable group members to express their emotions during the group session to enhance their quality of life and well-being.

It's all about them identifying their own emotions and reflecting on what they experiencing during the activity. It's about getting them to that sense of realization that what I have done, it creates different depths of thoughts for each person ... By facilitating the group members to share their experiences and emotions, they end up feeling that they could identify their emotions from others. This helps them to develop their emotional language and it equips them to know about themselves and that increases their spirituality and it is a form of healing. (Fourth-year student 8, personal communication, 2016)

To add on in the form, the clients will be busy with painting so you will facilitate and allow emotions to come out and use interactive to guide so that they can bring what they wrote down. I realize like reflecting on the activity one person in the group could identify so through activity selection spirituality maybe facilitated. (Fourth-year student 9, personal communication, 2016)

The participants indicated that some of the group members in mental health facilities tend to express fears about being a prisoner, isolated, and having family stresses. This may mean that the group members seemed to experience one of the outcomes of occupational injustice-particularly occupational alienation. According to Townsend and Wilcock (2004), occupational alienation is the absence of meaning or purpose in the occupations of daily life. Therefore, Bryant, Craik, and Mckay (2004) reported that experiences of occupational alienation could be expressed in a unique manner by an individual or shared within a group. 
I think activities created a space for self-expression in that sense. You could feel is a sense of relief for the group members, some of the things that came out we feel like prisoners because there are so many gates, they said they feel like prisoners, isolated, and the family depresses all these things came out. (Fourth-year student 6, personal communication, 2016)

The participants indicated that spirituality was associated with occupations and the psychosocial interactive approach. This assisted the group members to enhance their health and well-being as well as coping strategies. It was evident that social interactions as one of the occupations allowed group members to share their experiences in a group and brought back the sense of satisfaction and sense of belonging. This may explain why occupational therapy groups facilitate spirituality.

The occupations gave the group members the feeling of satisfaction to enhance their spirituality so that they can be positive. (Fourth-year student 4, personal communication, 2015)

\section{Make use of the resources to service the driver and vehicle}

The focus of the fourth theme is the participants, occupational therapists, and families of group members with mental illnesses. In order to explain this, the participants used the vehicular services to nurture and care metaphors to symbolize the use of resources to service the driver (facilitators) and the vehicle (the groups). Participants felt that they needed support to cope with the challenges of being an occupational therapy group facilitator. The participants explained it is important to establish a referral system that would assist with the inclusion of spiritual leaders as part of an interdisciplinary team in mental health facilities.

There is a need for a formal and informal referral system in order to help the clients. We should aim for our clients to be well and be independent in all spheres of their life. (Third-year student 3, personal communication, 2015)

The interdisciplinary team should accommodate spiritual leaders so that occupational therapists may refer clients at that hospital. (Third-year student 16, personal communication, 2015)

The driver metaphor was also used to express participants' feelings of burnout, emotional instability, and role demands of running occupational therapy groups. The participants stated that they also need support to cope with the demands of being a driver of the vehicle. This indicates that participants are also human beings who experience challenges in their occupations. As a result, the participants believed that they should use available resources for debriefing to offload the stresses and emotions encountered in their role demands of their social and working lives. Accordingly, the participants indicated that they should be well prepared because they will interact with group members from a variety of backgrounds. This meant the participants might need to have the emotional insight and imagination to understand the viewpoints of others to prevent non-maleficence.

I would like to say as occupational therapy students, we are also human beings; we should make use of supportive resources on campus. If it happens that you need to speak to someone and you haven't dealt with all 
the emotions. You actually do more harm not only to yourself but to the group. (Fourth-year student 6, personal communication, 2016)

Participants reported that they tend to forget about the family members of the mental health users attending occupational therapy groups. Therefore, the participants believed that families should be considered members of the interdisciplinary team in mental health facilities to enhance the quality of life, health, and well-being of the group members and their families. As indicated in the excerpt below, families of mental health users valued spirituality as a coping mechanism.

Spirituality has positive impacts on the family members of mental health users although we tend to forget them and solely focus on the client. Working in the outpatient unit [Mental Health Facility] with family support groups, the families shared about the value of prayer and meaningfulness of spirituality which gave them hope.

(Fourth-year student 10, personal communication, 2015)

\section{Discussion}

The present study sought to explore occupational therapy students' perceptions of spirituality in occupational therapy groups. Overall, the findings revealed participants believed that occupational therapy groups seemed to provide group members with time and space to express their spirituality through engaging in meaningful occupations. These findings can be explained in part by the number of previous studies which indicated that spirituality seems to be associated with occupation in occupational therapy (Howard \& Howard, 1997; Kang, 2003; Wilding, 2007). There are seven dimensions of spirituality that may contribute significantly to occupational therapy students' and occupational therapists' knowledge, awareness, and skills (Jones, 2016; Kang, 2003). These dimensions include: suffering, becoming, meaning, being, centeredness, connectedness, and transcendence. It has been emphasized that in a case where most or all of the dimensions are not met, this may result in impoverishment of the human spirit.

\section{Suffering}

Kirsh (1996) indicated occupational therapy narratives are used to make sense through stories and metaphors. Therefore, these participants used metaphors to make sense of their perceptions and experiences of spirituality in occupational therapy groups. Suffering is defined as state of severe distress associated with events that threaten intactness of human beings. It may influence individuals', groups', and communities' sense of spirituality and occupational performance in life (Egan \& DeLaat, 1994; Egan \& Swedersky, 2003; Johnston \& Mayers, 2005; Kirsh, 1996). Suffering seems to provide a rationale for embarking on the vehicle used here to symbolize occupational therapy groups, as it can affect the whole being including physical, emotional, mental, spiritual, and social aspects of a human being (Oreopoulos, 2005). In the themes "engagement in occupations facilitates spirituality" and "spiritual journey in occupational therapy groups," our study found that occupational therapy groups were mainly facilitated in group members who were suffering from a variety of mental illnesses such as trauma, stress, depression, and family stressors. This is consistent with the recent study by Ahmad Nabil, Saini, Nasrin, Bahari, and Sharip (2016) that explored the understanding of spirituality among Muslim patients with depression. The findings of 
Ahmad Nabil and colleagues (2016) indicated that patients with depression needed their spiritual needs to be met during the process of recovery. Some of these patients could not engage in their valued spiritual occupations like prayer.

The results of this study show that the participants were providing occupational therapy services to group members who were experiencing occupational disruption related to their mental illnesses. It is difficult to explain this result, but it might be related to the loss of meaning and purpose in life. Another possible explanation for this is that group members seem to suffer from occupational alienation. The travelers' fuel and energy for reaching the destination symbolized engagement in occupations to facilitate spirituality. Therefore, the findings indicate that the participants were relevant facilitators to alleviate group members' suffering through collaborative partnerships to identify meaningful occupations that seemed to be significant for the groups. This concurs with Oreopoulos' (2005) conclusion that healthcare professionals have a privileged role to help clients find meaning in their suffering. These occupations were identified through group members' occupational consciousness and occupational choices in preparation for the becoming dimension of spirituality.

\section{Becoming}

Becoming is the dimension of spirituality that was evident in the metaphor of the travelers' fuel for reaching the destination symbolizing the theme "engagement in occupations facilitates spirituality." It was evident that there was an association between personal occupational engagement and spirituality. This result may be explained by the fact that both occupation and spirituality are related to common human needs such as personal meaning, purpose, choice, self-worth, as well as the quality of experience and well-being (Hammell, 2004; Tse, Lloyd, Petchkosky, \& Manaia, 2005). Similarly, the participants' perceptions of spirituality in occupational therapy groups indicated that group members were regarded as social, spiritual, and occupational beings who engage independently in social situations to enhance their quality of life and well-being. This finding corroborates the views of Hess and Ramugondo (2014) and Tse and colleagues (2005) that spirituality is a social construct promoting group members' autonomy (ethical reasoning) and allowing them to express themselves in a form of social participation. It is important to emphasize that occupational therapy groups appeared as an enabler of spirituality and social participation because group members were motivated to engage in occupations. A possible explanation for this might be that the participants had an understanding of-and insight about-the psychosocial interactive model as an enabler of transformation in occupational therapy groups. Another possible explanation for this is that the participants who have used the psychosocial interactive model in practice were able to indicate how it supports spirituality through learning interaction skills in occupational therapy groups. This is consistent with Carroll (2015), which states occupational therapy groups assist group members with psychosocial life skills such as problem solving, day planning, and anger management. It can thus be suggested that occupational therapy students should be taught about the importance of the psychosocial interactive model in relation to integration of spirituality in occupational therapy groups. 
It is interesting to note that the occupational therapy students who participated in this study believed self-reflection facilitated spirituality among group members. Additionally, the students believed the types of activities that they selected were group members' occupational choices and elicited some form of self-expression as a part of the activity. Moreover, the participants' perception indicated that the occupational therapy groups provided a safe environment for the group members to share their experiences and emotions, which resulted in universality, connectedness, and increased self-worth. This also led the participants to consider occupational therapy groups as a vehicle for transporting and transferring emotions with each other to form a sense of healing. It was evident that meaningful occupations appeared as a facilitator for the group members' spirituality so that they experience feelings of satisfaction, which enhances their meaning.

\section{Meaning}

Meaning is the third dimension of spirituality; according to Kang (2003), meaning is defined as "the sense of intrinsic purposefulness and vitality rooted personal, collective, or transpersonal spaces that inform the direction of, and inspire the process of living" (p. 97). Meaning is one of the dimensions of spirituality that emerged in three themes: occupational therapy groups are a vehicle for spirituality, spiritual journey in occupational therapy groups, and engagement in occupation facilitates spirituality. The results of the current study show there was connectedness between the participants and the group members who attended occupational therapy groups. The connectedness assisted both the participants and the group members to explore how the stress, trauma, depression, and family stressors affected their engagement in occupations in order to find meaning for their illnesses. This finding concurs with Ahmad Nabil and colleagues' (2016) study, which indicated that some patients with depression were able to make sense of their suffering. There were, however, other patients who tended to complain, indicating they lacked meaning when thinking of their suffering.

The results of this study indicated that the student participants formed a collaborative partnership with the group members. This seems to be in line with Schneider Corey and colleagues' (2013) and Knowles' (2002) view that collaborative therapeutic relationships in groups provide a space and time for self-discovery in order to find meaning. Additionally, Knowles (2002) suggested adults should acquire a mature understanding of themselves and their rights in order to achieve their goals, needs, interests, and capabilities.

Another aspect of meaning dimension of spirituality in occupational therapy groups was the norming stage of group development. The participants' perceptions indicated that the group members in the norming stage managed to find meaning as they set goals based on their needs such as belonging, selfworth, and control over choices. This finding supports Knowles' (2002) adult learning principles-particularly the idea that adults should be given the freedom to develop an attitude of acceptance, love, and respect toward others. As in our study, occupational therapy groups were found to allow group members to develop their goals, which also aligned with those of occupational therapy students. As a result, the group members found meaning because their goals were to "to get better, to get out of the hospital, be healed," as reported by the participants. These goals were achieved because the 
participants reported that "our goal in occupational therapy is to assist our clients to find meaning for what they are doing but not telling them what to do and by allowing them to identify their own purpose" (Fourth-year student 6, personal communication, 2016). Eventually, the occupational therapy groups enhanced the group members' quality of life and well-being. This is evident in a statement by one of the participants: "the group members agreed on that they felt humane at the end it was a spiritual thing for the group" (Fourth-year student 10, personal communication, 2016). As a result, the group members were connecting with self, which led to the being dimension of spirituality.

\section{Being}

In this dimension, being is regarded as "a pervasive quality that forms the foundations of our experience as human beings" (Kang, 2003, p. 97). Being as a dimension of spirituality was identified in the first three themes (Occupational therapy groups are a vehicle for spirituality, spiritual journey in occupational therapy groups, and engagement in occupation facilitates spirituality). In this study, the travelers represented the person-centered and humanistic approaches, which allowed group members to share their emotions through reflections during occupational therapy groups. Similarly, Hess and Ramugondo (2014) and Swinton as cited by Hoyland and Mayers (2005) asserted the therapeutic relationship relates to engaging in an experiential journey with others, and communicating, understanding, and a willingness to be with the other, which denotes spiritual care. This was evident in the current study in the wheels symbolizing the stages of group development-particularly the norming stage-as the drivers (occupational therapy students) used themselves therapeutically by listening in an active and sensitive way to the group members. As a result, the participants were able to allow the group members to share their personal experiences while going with the flow, rather than trying to direct the way the group is moving until group members were able to tap into their spirituality. These findings agree with findings of previous studies, which found that spiritual needs seem to incorporate respect, listening, the right to dignity and choice, cultural sensitivity, and lifestyle as well as space (Hoyland \& Mayers, 2005; Johnston \& Mayers, 2005; Udell \& Chandler, 2000). This is in line with Corey and colleagues' (2015) view of leading a group while allowing the group members to share and explore their spiritual and religious needs. In contrast to earlier findings, however, no evidence of time constraints, feeling uncomfortable with spirituality, or a lack of spiritual care were detected as barriers to meeting spiritual needs.

\section{Centeredness}

Centeredness is defined as "an inner stability based on knowing and recognizing that which lies at the core of one's being" (Kang, 2003, p. 98). The participants in the study expressed the view that some of the group members were independently engaging in meditation. This appeared as one of the strategies that assisted group members to tap into their spirituality. Therefore, this idea is consistent with Morris (2013), who indicated occupational therapists that acknowledge humanistic concerns and believe in connectedness seemed to practice spiritual care with clients in need of connection with the world.

Additionally, the findings indicated that family members were connecting with God through prayer, which can be effective in strengthening their hope. In a study by Borzou, Anosheh, 
Mohammadi, and Kazemnejad (2014), they found that believing in God's greatness and engaging in spiritual occupations such as praying was a method of religious coping.

The participants' perceptions indicated that visualization of one's life journey using the Kawa model assisted them in understanding their spirituality. This is further evidence of narrative reasoning-participants used their life stories to understand, interpret, and encourage group members to revise their lives in a positive manner irrespective of obstacles. Therefore, the finding seems to support self-reflection as a tool of practice that the participants used to share their experience about spirituality in occupational therapy groups.

In Hess and Ramungondo's (2014) study, a sense of interdependence was found to be part of the connectedness dimension of spirituality between the occupational therapists and mental health system users. Similarly, the findings in the current study revealed that the group members were given the opportunity to connect with each other and the student therapists, and this was the essence of spirituality.

\section{Connectedness}

This is a dimension of spirituality: seeing the self as a fluid process embedded within a larger interrelational context. Spiritual connection "refers to the extent of connectedness to a spiritual being that helps a person to get through hard times and tolerate stress" (Lopez et al., 2014, p. 387).

Connectedness is one of the dimensions of spirituality that was described in all the themes: occupational therapy groups are a vehicle for spirituality, spiritual journey in occupational therapy groups, engagement in occupation facilitates spirituality, and make use of the resources to service the driver and vehicle. The participants' perceptions of connectedness as a dimension of spirituality appeared as a bond that linked all the metaphors representing the themes. The findings indicated that the occupational therapy groups appear to have the driving forces which foster connectedness and health through spirituality in occupational therapy. The driving forces metaphors that symbolized the curative factors were group cohesiveness, installation of hope, altruism, universality, catharsis, and interpersonal learning. It is therefore likely that such connections exist between the participants and the group members because of forces that allowed them to share their experiences and emotions to enhance their being, meaning, and self-worth. As a result, the group members were able to ventilate in the occupational therapy group, which strengthened the connectedness. These findings appear to be consistent with Tse and colleagues' (2005) explanations of connectedness' benefits as a dimension of spirituality that makes a unique contribution to healing and recovery for mental health users, including coping, social support, hope, and self-esteem. Hence, Ahmad Nabil and colleagues (2016) and Cassell (1999) highlighted the importance of sensitivity and empathy through connectedness during one's suffering with the significant others being doctors and family members.

In relation to coping, the participants' perceptions in the current study revealed that group members appear to use spirituality as a resource for coping mechanisms. Additionally, the 
participants indicated that the family members of the mental health users tend to be forgotten as part of the connectedness dimension of spirituality. Some of the participants, however, highlighted the view that family members seem to use connections with God through prayer in order to cope with the caring task for their significant family members with mental illnesses. The findings of the current study corroborate the findings of Ahmad Nabil and colleagues' (2016) study, which found that some of the patients ventilated with family members and healthcare professionals to obtain a sense of relief. It can therefore be suggested that family members of the users should be constantly involved in caring for the significant other. This suggestion is in accordance with Fang, Sixsmith, Sinclair, and Horst (2016) and Hess and Ramugondo's (2014) studies that suggested healthcare professionals must carefully consider the involvement of family members and their roles in the caring process in order to provide sensitive care. Regarding hope and self-esteem, the findings of the current study indicated participants believed that spiritual connections provided group members with a sense of hope, which gave them the strength to continue with their desires and goals. These findings are consistent with Tse and colleagues (2005), who found that hope enhances mental health users' sense of purpose and meaning in life.

From our study, participants identified the finding that there was a need for the interdisciplinary team to accommodate community pastoral care and spiritual leaders to strengthen the health services as well as a pastoral care referral system for mental health users. These results indicate the participants believed that the connectedness dimension of spirituality could be used for health promotion by creating supportive environments to improve the health and well-being of mental health users and populations. This study produced results which corroborate the findings of a great deal of previous work in this field of spirituality in occupational therapy and interdisciplinary dialogue (Hess \& Ramugondo, 2014; Thompson \& MacNeil, 2006).

The findings of this study indicate the wellness of the participants and other healthcare professionals working in mental health facilities seem to be influenced by the demands of their work roles and responsibilities, which can lead to burnout. The present findings seem to be consistent with other research, which found that the nurses and occupational therapy students as well as therapists experience drainage, feelings of shock, blame and condemnation, inadequacy, and the fear of reprisal (Egan \& DeLaat, 1994; Matandela \& Matlakala, 2016). As a result, these studies and the findings of the current study suggest that there must be support strategies and an ongoing program to assist healthcare professionals to deal with their emotions in order to carry out their work effectively.

\section{Transcendence}

According to findings in recent studies, participants' perceptions revealed that transcendence was one of the dimensions of spirituality which assisted group members to develop suffering strategies. The participants reported that the goals of the group members in occupational therapy groups appeared to facilitate coping strategies. The group members were better able to cope with their stress, depression, and trauma. As a result, the group members experienced a sense of relief from their suffering. 


\section{Implications of the study}

Occupational therapy students stated their perceptions of spirituality's role in occupational therapy groups. This study provided the students with an opportunity to share their views, which could in the future assist in an integration of spirituality into occupational therapy education. There are numerous implications for occupational therapy education and practice in reference to spirituality in occupational therapy groups. First, students indicated that spirituality facilitates connectedness among group members in occupational therapy groups. Therefore, the findings of our study may help therapists and students consider integrating spirituality as an important element of groups. Second, students indicated that the psychosocial interactive model enables group members to share their emotions in occupational therapy groups, which facilitates self-reflection and interpersonal learning. It is clear that students and therapists could learn to incorporate spirituality into occupational therapy groups using the psychosocial interactive model. Third, it was evident that the norming stage of group development enabled group members to learn to accept other group members based on their culture, religion, and spirituality. This related to Bennett's model of cultural sensitivity (1993), which assisted group members to experience cohesiveness and universality. Fourth, the findings indicated participants believed that students and therapists should understand their position about spirituality prior to using such an approach in occupational therapy groups. Fifth, from the findings, it was clear that occupation was used as a conduit for spirituality in occupational therapy groups, which assisted group members to find meaning and purpose in life. Lastly, the students indicated that they need support because some of the demands of facilitating occupational therapy groups tend to be draining and taxing. Therefore, these findings suggested that there must be a supporting program for therapists and students within the mental health facilities to prevent burnout.

A limitation of the current study is that the findings may not be generalized to other occupational therapy students and institutions of higher learning. This indicates a need for further research to be conducted with students from other institutions in order to enhance the body of knowledge related to spirituality and occupational therapy groups.

\section{Conclusion}

This study explored occupational therapy students' perceptions of spirituality in occupational therapy groups during the group fieldwork process. Overall, the findings of the study provided deeper understanding and expanded our insight into the phenomenon of spirituality in occupational therapy groups. This study has shown that occupational therapy groups contributed significantly to group members' self-awareness, meaning, and purposetogether with connectedness with others. The current findings clearly support the relevance of the psychosocial interactive approach to facilitating relationships among spirituality, occupation, and mental health in occupational therapy groups. The students indicated that the stages of group development appeared to facilitate the spiritual journey in occupational therapy groups-providing the group members with an opportunity to experience change in their lives. The evidence from this study suggests that occupational therapists and students 
should consider developing collaborative partnerships with families and spiritual leaders in the community to meet the spiritual needs of clients.

\section{Acknowledgements}

The authors would like to thank the University of the Western Cape for granting permission to conduct the study. We are grateful for all the participants and for their participation in the study.

\section{Funding}

This work is based on the research supported in part by the National Research Foundation (NRF) of South Africa for the grant Unique Grant No. 93992. Any opinion, finding, and conclusion or recommendation expressed in this material is that of the author(s), and the NRF does not accept any liability in this regard. 


\section{References}

Ahmad Nabil, M. R., Saini, S. M., Nasrin, N., Bahari, R., \& Sharip, S. (2016). I can't prayThe spiritual needs of Malaysian Muslim patients suffering from depression.

International Journal of Malaysia, 15(1), 103-109.

Bell, T., Wegner, L., Blake, L., Jupp, L., Nyabenda, F., \& Turner, T. (2015). Clients' perceptions of an occupational therapy intervention at a substance use rehabilitation centre in the Western Cape. South African Journal of Occupational Therapy, 45(2), 10-14. doi:10.17159/2310-3833/2015/v45n2a3

Bennett, M. J. (1993). Towards ethnorelativism: A developmental model of intercultural sensitivity. In R. M. Paige (Ed.), Education for the intercultural experience (pp. 2171). Yarmouth, ME: Intercultural Press.

Borzou, S. R., Anosheh, M., Mohammadi, E., \& Kazemnejad, A. (2014). Patients' perception of comfort facilitators during hemodialysis procedure: A qualitative study. Iranian Red Crescent Medical Journal, 16(7), e19055. doi:10.5812/ircmj.19055

Braun, V., \& Clarke, V. (2006). Using thematic analysis in psychology. Qualitative Research in Psychology, 3(2), 77-101. doi:10.1191/1478088706qpo63oa

Bryant, W., Craik, C., \& McKay, E. A. (2004). Living in a glasshouse: Exploring occupational alienation. Canadian Journal of Occupational Therapy, CAOT Publications ACE, 71(5), 282-289. doi:10.1177/000841740407100507

Carroll, E. (2015). Towards client-centred practice within an occupational therapy group life skill program: An action research journey (Master's thesis). University of the Free State, Bloemfontein, South Africa.

Cassell, E. J. (1999). Diagnosing suffering: A perspective. Annals of Internal Medicine, 131(7), 531-534. doi:10.7326/o003-4819-131-7-199910050-00009 Cole, M. B., \& Donohue, M. (2011). Social participation in occupational therapy: In schools, clinics and communities. Thorofare, NJ: Slack Inc.

Corey, G., Schneider Corey, M., Corey, C., \& Callanan, P. (2015). Issues and ethics in the helping professions (9th ed.). Belmont, CA: Brooks/Cole, Cengage Learning.

Dawson, S. (1993). The role of occupational therapy groups in an Australian hospice. American Journal Hospice Palliative Care, 10(4), 13-17. doi:10.1177/104990919301000406

De Jongh, J. (2009). An innovative curricula change to enhance occupational therapy student practice. South African Journal of Occupational Therapy, 39(1), 31-38.

Donica, K. (2008). The application of psychospiritual integration frame of reference. Physical \& Occupational Therapy, 27(2), 107-121. doi:10.1080/02703180802206082

Duncombe, L. W., \& Howe, M. C. (1985). Group work in occupational therapy: A survey of practice. The American Journal of Occupational Therapy, 39(3), 163-170. doi:10.5014/ajot.39.3.163

Egan, M., \& DeLaat, M. D. (1994). Considering spirituality in occupational therapy practice. Canadian Journal of Occupational Therapy, 61(2), 95-101.

doi:10.1177/000841749406100205

Egan, M., \& Swedersky, J. (2003). Spirituality as experienced by occupational therapists in practice. The American Journal of Occupational Therapy, 57(5), 525-533. doi:10.5014/ajot.57.5.525 
Ellis, R. (2008). Learner beliefs and language learning. The Asian EFL Journal Quarterly, 1O(4), 7-25.

Fang, M. L., Sixsmith, J., Sinclair, S., \& Horst, G. (2016). A knowledge synthesis of culturally and spiritually-sensitive end-of-life care: Finding from scoping review. BioMed Central Geriatrics, 16(107). doi:10.1186/s12877-016-0282

FinLay, L. (1993). Groupwork in occupational therapy. London, England: Chapman \& Hall, Nelson Thornes.

Friese, S. (2014). Qualitative data analysis with ATLAS.ti (2nd ed.). London, England: Sage Publications.

Grove, S. K., Burns, N., \& Gray, J. R. (2013). The practice of nursing research: Appraisal, synthesis, and generation of evidence (7th ed.). St Louis, MO: Elsevier, Saunders.

Hammell, K. W. (2004). Dimensions of meaning in the occupations of daily life. Canadian Journal of Occupational Therapy, 71(5), 296-305.

doi:10.1177/000841740407100509

Hess, K. Y., \& Ramugondo, E. (2014). Clinical reasoning used by occupational therapists to determine the nature of spirituality occupations in relation to psychiatric pathology. British Journal of Occupational Therapy, 77(5), 234-242. doi:10.4276/030802214×13990455043449

Howard, B. S., \& Howard, J. R. (1997). Occupation as a spiritual activity. The American Journal of Occupational Therapy, 51(3), 181-185. doi:10.5014/ajot.51.3.181

Hoyland, M., \& Mayers, C. (2005). Is meeting spiritual need within the occupational therapy domain? The British Journal of Occupational Therapy, 68(4), 177-180. doi:10.1177/030802260506800406

Janse van Rensburg, A. B. R., Poggenpoel, M., Szabo, C. P., \& Myburgh, C. P. H. (2014). Referral and collaboration between South African psychiatrists and religious or spiritual advisers: Views from some psychiatrists. South African Journal of Psychiatry, 20(2), 40-45. doi:10.7196/SAJP.533

Johnston, D., \& Mayers, C. (2005). Spirituality: A review of how occupational therapists acknowledge, assess and meet spiritual needs. British Journal of Occupational Therapy, 68(9), 386-392. doi:10.1177/030802260506800902

Jones, J. (2016). A qualitative study exploring how occupational therapists embed spirituality into their practice (Doctoral thesis). University of Huddersfield, Huddersfield, West Yorkshire, England.

Joyce, J., \& Warren, A. (2016). A case study exploring the influence of a gardening therapy group on well-being. Occupational Therapy in Mental Health, 32(2), 203-215. doi:10.1080/0164212x.2015.1111184

Kang, C. (2003). A psychospiritual integration frame of reference for occupational therapy. Part 1: Conceptual foundations. Australian Occupational Therapy Journal, 50, 92103. doi:10.1046/j.1440-1630.2003.00358.x

Kirsh, B. (1996). A narrative approach to addressing spirituality in occupational therapy: Exploring personal meaning and purpose. Canadian Journal of Occupational Therapy, 63(1), 55-61. doi:10.1177/000841749606300107

Knowles, M. (2002). Malcom Knowles informal adult education, self-direction, and 
andragogy. The Encyclopedia of Informal Education. Retrieved from http://infed.org/mobi/malcolmknowles-

informal-adult-education-self-direction-and-andragogy/

Lopez, V., Fischer, I., Leigh, M. C., Larkin, D., \& Webster, S. (2014). Spirituality, religiosity, and personal beliefs of Australian undergraduate nursing students. Journal of Transcultural Nursing, 25(4), 395-402. doi:10.1177/1043659614523469

Marmarosh, C., Holtz, A., \& Schottenbauer, M. (2005). Group cohesiveness, group-derived self-esteem, group-derived hope and the well-being of group therapy members. Group Dynamics: Theory. Research, and Practice, 9, 32-44.

Matandela, M., \& Matlakala, M. C. (2016). Nurses' experiences of inpatients suicide in a general hospital. Health South African Gesondheid, 21, 54-59.

doi:10.1016/j.hsag.2015.10.001

McColl, M. A. (2011). Models of spirituality, occupation and health. In M. A. McColl. (Ed.), Spirituality and occupational therapy (2nd ed., pp. 91-101). Ottawa, ON, Canada: CAOT Publications ACE.

Morris, D. N. (2013). Perceptions of spirituality and spiritual care in occupational therapy practice. Occupational Therapy in Mental Health, 29(1), 60-77. doi:10.1080/0164212X.2013.761109

O’Brien, J. C. (2013). Occupational analysis and group process. In J. C. O’Brien \& J. W. Solomon (Eds.), Occupational analysis and group process (pp. 1-5). St Louis, MO: Elsevier/Mosby.

O'Donnell, N. (2008). Group therapy: Reaching fulfilment with other. Studies of Psychology

Publishing Catholic University of Lublin (Studia z Psychologii Wyd. Katolickim Uniwersytecie Lubelskim), 15, S27-S37.

Oreopoulos, D. G. (2005). Is there meaning in suffering? Humane Medicine, 5(2). Retrieved from

http://www.hektoeninternational.org/documents/ISTHEREMEANINGINSUFFERIN G.pdf

Pishghadam, R., \& Pourali, S. (2011). Iranian PhD students' beliefs about language learning and teaching: A qualitative study. Word Journal of Education, 1(1), 63-71. doi:10.5430/wje.v1n1p63

Polatajko, H. J., Townsend, E. A., \& Craik, J. (2007). Canadian model of occupational performance and engagement (CMOP-E). In E. A. Townsend \& H. J. Polatajko. (Eds.), Enabling occupation II: Advancing an occupational therapy vision of health, wellbeing, \& justice through occupation (pp. 22-36). Ottawa, ON, Canada: CAOT Publications ACE.

Saban, A. (2004). Prospective classroom teachers' metaphorical images of selves and comparing them to those they have of their elementary and cooperating teachers. International Journal of Educational Development, 24, 617-635.

doi:10.1016/j.ijedudev.2004.03.003

Schneider Corey, M., Corey, G., \& Corey, C. (2013). Group process and practice (9th ed.). Belmont, CA: Brooks/Cole, Cengage Learning.

Scientific Software. (2016). Atlas.ti 7. ATLAS.ti scientific software development GmbH, 
Berlin. Retreived from http://www.atlas.com/index.html

Smith, S., \& Suto, M. J. (2014). Spirituality in bedlam: Exploring patient conversation on acute psychiatric units. Canadian Journal of Occupational Therapy, 8(1), 8-17. doi:10.1177/0oo8417413516932

Soomar, N. (2015). Addressing spirituality in group therapy: A qualitative study at a shelter for abused and vulnerable Muslim women in Durban, South Africa (Master's Thesis). University of KwaZulu-Natal, Durban, South Africa.

Stein, F., \& Tallant, B. K. (1988). Applying the group process to psychiatric occupational therapy Part 2: A model for a therapeutic group in psychiatric occupational therapy. Occupational Therapy in Mental Health, 8(3), 29-51.

Stein, F., \& Tallant, B. K. (2013). Applying the group process to psychiatric occupational Therapy Part 1: Historical and Current use. In D. Gibson (Ed.), Group Process and Structure in Psychosocial Occupational Therapy (pp. 9-28). New York, London: The Haworth Press.

Suto, M. J., \& Smith, S. (2014). Spirituality in bedlam: Exploring professional conversations on acute psychiatric units. Canadian Journal of Occupational Therapy, 8(1), 18-28. doi:10.1177/00o8417413516931

Terre Blanche, M., Kelly, K., \& Durrheim, K. (2006). Why qualitative research? In M. Terre Blanche K. Durrheim, \& D. Painter (Eds.), Research in practice: Applied methods for the social sciences (pp. 271-284). Cape Town, South Africa: UCT Press.

Thompson, B. E., \& MacNeil, C. (2006). A phenomenological study exploring the meaning of a seminar on spirituality for occupational therapy students. The American Journal of Occupational Therapy, 6o, 531-539. doi:10.5014/ajot.60.5.531

Townsend, E., \& Wilcock, A. A. (2004). Occupational justice and client centered practice: A dialogue in progress. Canadian Journal Occupational Therapy, 71, 75-87. doi:10.1177/000841740407100203

Tse, S., Lloyd, C., Petchkosky, L., \& Manaia, W. (2005). Exploration of Australian and New Zealand indigenous people's spirituality and mental health. Australian Occupational Therapy Journal, 52, 181-187. doi:10.1111/j.1440-1630.2005.00507.x

Udell, L., \& Chandler, C. (2000). The role of the occupational therapist in addressing the spiritual needs of clients. British Journal of Occupational Therapy, 63(10), 489-494. doi:10.1177/030802260006301006

Wilding, C. (2007). Spirituality as sustenance for mental health and meaningful doing: A case illustration. Medical Journal of Australia, 186(10), S67-S69.

Yalom, I., \& Leszcz, M. (2005). The theory and practice of group psychotherapy (5th ed.). New York, NY: Basic Books.

Zinnbauer, B. J., \& Camerota, E. C. (2004). The spirituality group: A search for the sacred. The Journal of Transpersonal Psychology, 36(1), 50-65. 